\title{
A systematic literature review exploring the psychosocial aspects of palliative care provision for incarcerated persons: A human rights perspective
}

\author{
$\underline{\text { ABSTRACT }}$ \\ Purpose - To explore the psychosocial aspects of palliative care provision for incarcerated \\ persons drawing on a human rights perspective
}

Design/methodology/approach - Seven databases were searched to identify empirical studies published from 2010 - 2020. Articles included were qualitative, quantitative, mixed methods, written in English, westernized health/prison settings, with a key focus on the psychosocial aspects of palliative care provision and human rights. The quality of the articles was appraised using the Mixed Methods Assessment Tool (MMAT) (2018).

Findings - The results from 26 articles revealed multiple models of care, with the US prison hospice program depicted as optimal, due to use of trained incarcerated caregivers, working as aides to the interprofessional team. The bereavement needs of caregivers were highlighted. Barriers to adequate psychosocial care were negative public discourse, prison processes and resources, provider attitudes and the incarcerated person's level of knowledge and trust. Identified facilitators related to incarcerated persons' caregiving programs, a sense of purpose and visitation leniency. Human rights principles were identified in studies that featured Compassionate Release (CR) and Advance Care Planning (ACP).

Practical Implications - Understanding the importance of psychosocial care for incarcerated persons with a life-limiting illness requires a shift in negative public discourse and the need for a stronger human rights focus. Some countries, such as the USA and UK are achieving effective outcomes, however, countries such as Australia are yet to contribute to this knowledge base. 
Originality/value - If palliative care is a human right, then its philosophy should be considered in its entirety, with the inclusion of psychosocial care.

Key words: palliative care, end-of-life, terminally ill, prisons, incarceration, psychosocial, human rights

The project was undertaken in accordance with PRISMA guidelines and registered with PROSPERO (Reference no. CRD42020209416).

\section{Introduction}

In 2018, there were an estimated 11 million individuals incarcerated in correctional institutions worldwide (Walmsley, 2019). Approximately 20\% of the USA prison population is aged over 50 years, with 17\% in the UK and 15\% in Australia (Age UK, 2019; Australian Institute of Health and Welfare [AIHW], 2020; Federal Bureau of Prisons, 2020). Prison life accelerates the ageing process due to the physical environment and poor health care, meaning individuals often present physiologically 10 - 15 years older than their chronological age (Merkt et al., 2020). Lifestyle behaviours prior to incarceration, further compound the issue, resulting in an increased demand for palliative and end-of-life (EOL) care (AIHW, 2019; Panozzo et al., 2020).

The United Nations Declaration of Human Rights (UNDHR) recognizes all persons have "inherent dignity and equal and inalienable rights" (United Nations, 1948, p.1). These rights are imperative when addressing needs for terminally ill incarcerated persons. For example, Article 5 states no one should be subject to degrading treatment, which includes treatment that causes fear, a sense of inferiority or mental suffering. Article 25 declares every person has a right to a standard of living adequate for health and well-being, including necessary social services (United Nations, 1948). Additionally, Articles 1 and 2 of the International Covenant on Civil and Political Rights (ICCPR) state all peoples have the right to self-determination, with a right to respect regardless of status (United Nations, 1966). 
The World Health Organization (WHO) purport prisoners have a right to health care equivalent to the standard available in the community (2014). In 2017, the United Nations added palliative care and stipulated that a dignified death is a human right for all. The principle of equivalence consequently underpins international standards and national policies, serving as a benchmark for health care delivery (AIHW, 2014; 2019). Failing adequate end-of-life care provision for an individual in prison would contravene the above-stated directive and compromise human rights (Handtke et al., 2017). Sub-standard treatment or withholding of health care should never be part of punishment (Australian Healthcare Associates [AHA], 2019).

Compassionate release is a provision founded on humanitarian reasoning, which allows terminally ill incarcerated persons facing imminent death to be released prior to sentence completion (Handtke et al., 2017). Early release enables access to palliative care services, including psychosocial care provision; a notion now considered a basic human right (Puru, 2018; Stajduhar et al., 2019). Whilst most western jurisdictions have release provisions, utilization is low (Kanbergs et al., 2019), which the literature attributes to a lack of policy awareness, unclear eligibility criteria, burdensome processes and unrealistic time frames (Handtke et al., 2017; Pazart et al., 2018; Price, 2018).

The WHO (2002) defines palliative care as an approach that aims to relieve suffering by addressing physical, psychological, social and spiritual needs of patients and family members. Other palliative care literature includes emotional, cultural and bereavement needs in defining the psychosocial domains (Ong, 2005; Reith and Payne, 2009; Sheldon, 1997). However, balancing end-of-life care needs with custodial demands and security concerns requires careful deliberation (McParland and Johnston, 2019). Compassionate release is often justified on the basis that the incarcerated person is too impaired to cognitively comprehend their punishment or pose a risk, highlighting that the goals of prison, namely rehabilitation and punishment, are no longer plausible (Handtke et al., 2017). 
As incarcerated persons age, health issues, mobility, frailty, and dementia all become concerns (Turner et al., 2018). Alongside these, corresponding psychosocial needs also develop. Family contact often reduces over time and in-prison support networks may diminish (Puru, 2018). Existential distress, a fear of dying alone or dying within a hostile system, highlight concerns beyond physical pain (Kanbergs et al., 2019; Sanders et al., 2018). Supporting meaningful relationships between ill incarcerated persons and their social networks may foster a sense of psychological security and stability, which are important in alleviating end-of-life distress (AIHW, 2014). Furthermore, psychosocial care could be enhanced if prison staff were educated on the holistic nature of palliative care and its connection to human rights. Prisoner advocates can raise awareness of the needs for terminally ill incarcerated people to create scope for more targeted support (AHA, 2019).

This paper examines the psychosocial aspects of palliative care provision for incarcerated persons utilizing a human rights perspective. Three key research questions guided the process:

1. What are some current approaches undertaken by prisons to deliver palliative care (including psychosocial care) to terminally ill incarcerated persons?

2. What are the barriers and facilitators to psychosocial care provision for terminally ill incarcerated persons?

3. How are human rights considered when addressing needs of terminally ill incarcerated persons?

\section{Methodology}

To address the topic, a systematic literature review was undertaken as the first phase of a larger study, in accordance with the Preferred Reporting Items for Systematic Reviews and Meta-Analyses (PRISMA) guidelines (Moher et al., 2009). The inclusion articles were 
appraised using the Mixed Methods Appraisal Tool (MMAT) Tool. Subsequently, the Braun and Clark (2006) method was utilized for thematic analysis so key themes could be identified, followed by a narrative synthesis. The study was conceptualised by a human rights framework, which also served to inform the development of the research questions.

\section{Eligibility criteria:}

The inclusion criteria incorporated qualitative, quantitative, and mixed methods studies from January $1^{\text {st }}, 2010$ - June $30^{\text {th }}, 2020$. This period has seen significant advances in prisoner health and human rights. Papers needed to be original, peer-reviewed, full text and in English to ensure consistency during appraisal. Grey literature such as literature reviews, conference papers, dissertations/thesis or commentaries were excluded, along with articles that lacked a palliative or end-of-life care focus.

\section{Literature search:}

In August 2020, seven databases were searched that regularly published articles relating to health and corrections - CINAHL, PsychInfo, Web of Science, Scopus, Proquest, Medline and PubMed. An experienced librarian was consulted for advice regarding the search terms, resulting in five combinations of search terms being utilised to answer the three research questions. All combinations included the search terms ("Palliative care" or "end of life care" or "advanced care" or "terminal illness" or "advanced illness") AND ("prison*" or "jail*" or "Gaol*" or "Incarcerated*" or "correction* services"). These two clusters of search terms were combined with either "human right*", ("hurdle*" OR "inhibitor*" OR "limit*" OR "obstacle*" OR "challenge*"), ("facilitator* OR "promote*" OR "enhance" OR "enabler" OR "support"), ("spiritual" OR "cultural" OR "Chaplaincy"), or "Hospice”.

\section{Screening and data extraction:}

An Excel spreadsheet was utilised to organize the data extraction process. A series of headings were formulated for this purpose - authors, title, year, country study aim, 
participants, study design and themes. Uncertainties relating to eligibility and quality of the article were discussed in depth by two of the researchers until consensus was attained.

The initial database search revealed 393 articles. 146 duplicates were removed. A hand search of article reference lists identified an additional 19 articles. The remaining articles $(n=266)$ titles and abstracts were then scrutinised against the predefined inclusion criteria, resulting in an additional 225 articles being removed. The two researchers then read the remaining articles $(n=41)$ in full and excluded an additional 13 articles due to not meeting the inclusion criteria, as depicted in the PRISMA flow diagram (Insert Figure I).

\section{MMAT appraisal tool}

The Mixed Methods Appraisal Tool (MMAT) (2018) demonstrates excellent interrater reliability and is recognised as the most reliable tool for appraising mixed methods studies. It can assess whether a study's method attains a pre-determined criterion, indicating methodological quality for mixed methods, qualitative and quantitative studies (Gledhill et al., 2017; Hong et al., 2018). The appraisal process was undertaken by two researchers to ascertain methodological quality of the existing articles $(n=28)$. The two researchers delegated the final articles $(n=28)$ between themselves and then cross - checked $25 \%$ of each other's MMAT results, selected at random. When appraisal results were queried, two of the researchers discussed at length until agreement was reached. Two articles were removed from the final selection group due to not meeting the MMAT criteria, resulting in the final total of 26 articles. The total mean score of the 26 articles was $81.5 \%$, with the lowest score being $60 \%$ and highest being $100 \%$.

\section{Data analysis:}

Completed extracted data were imported into NVivo 12, a qualitative data analysis system. Braun and Clarke's (2006) thematic analysis were applied by using a "line-by-line" 
approach to search for initial common themes. Themes were then reviewed in relation to the research questions. By adopting a narrative synthesis approach, answers to the questions could be ascertained (McParland and Johnston, 2019). To uphold rigour, this process was undertaken by two of the researchers and then discussed with the whole research team.

\section{Results}

This study was undertaken to investigate three questions relating to palliative and psychosocial care provision and human rights considerations in a prison context. The inclusion/exclusion criterion resulted in a final selection of articles comprising 15 qualitative, seven quantitative, and three mixed methods studies. The results from the Depner et al. study was disseminated across two articles $(2017 ; 2018)$, meaning there were 26 articles overall, but 25 studies in total. The studies were from the USA $(n=16)$; UK $(n=4)$; France $(n=2)$; Switzerland ( $\mathrm{n}=2)$; and Australia $(\mathrm{n}=1)$.

(Insert Table I)

Question 1: What are some current approaches undertaken by prisons to deliver palliative care (including psychosocial care)?

Internationally, the approaches to providing palliative and EOL care in prisons are varied. For example, in the USA, prison-based hospices (e.g. the Louisiana State Penitentiary [LSP] model) use volunteer incarcerated caregivers to assist with EOL support (Cloyes et al., 2017; Supiano et al., 2014). Stephens et al. (2019) stated there are 75 prison hospice facilities operating across the country, with the LSP model being the most featured. However, despite the increase, integrating on-site hospices into other US prisons remains limited and disparate. Not all US prisons utilise incarcerated hospice volunteers to assist with psychosocial cares (Depner et al., 2018 Loeb et al., 2014). 
In the UK, incarcerated persons are patients of the National Health Service (NHS) so are therefore entitled to external care (Turner et al., 2018). Many UK prisons are linked to specialist palliative care providers (e.g. hospices); with the incarcerated person often released for end-of-life care under licence. Once outside the prison, psychosocial care can be accessed (Lillie et al., 2016, Turner et al., 2018). In France, prisons have their own health care unit, or alternatively local hospitals have designated wards for incarcerated people. Research reveals incarcerated persons prefer hospital care as they feel like a 'legitimate' patient (Chassagne et al., 2017, p. 71). Swiss prisons are in a time of transition and it was not clear from the articles what approaches are taken to deliver palliative care.

In Australia, prisons are governed by state and territory jurisdictions, leading to diverse service delivery. Terminally ill persons are either cared for within prisons by contracted external health care professionals or relocated to a maximum-security prison closer to a tertiary or secondary provider, resulting in some declining treatment as they would be removed from social networks (Panozzo et al., 2020). Differences between countries in palliative care delivery approaches, inclusive of psychosocial care, are evident. The UK adopts a 'within reach model', while France uses a 'designated hospital ward' approach and Australia uses a 'relocation' strategy. However, palliative and EOL care are more complex in the US, with an array of models being implemented. The findings revealed prison hospice programs and its use of incarcerated caregivers to assist with psychosocial care are increasing and attaining a strong evidence base.

Question 2 - What are the barriers and facilitators to psychosocial care provision for terminally ill incarcerated individuals?

Dominant psychosocial concerns were loneliness and dying alone; anxiety about pain and needs being adequately met at end-of-life; existential distress and the need to feel 
humanized; fear about dying whilst incarcerated; limited social support from family and friends (including incarcerated relatives) (Cloyes et al., 2014; Cloyes et al., 2015b; Depner et al., 2017; Depner et al., 2018; Kanbergs et al., 2019; Loeb et al., 2014). Additionally, the Panozzo et al. (2020) article revealed how undertaking important cultural and religious practices, both before and after death, are limited by prison protocols. The literature was deductively analysed for barriers (negative influences) and facilitators (supportive influences) on the delivery of psychosocial care. Six sub-themes were identified.

\section{Barriers}

\section{Public Discourse and Inherent Tensions}

Six articles spoke to the negative influence of public discourse on the delivery of psychosocial aspects of palliative care (Handtke et al., 2017; Hoffman and Dickinson, 2011; Marti et al., 2017; Penrod et al., 2014; Turner et al., 2011; Turner et al., 2018). Crimes stratified by harm, were directly connected to public sympathy (Turner et al., 2018) with incarcerated individuals who commit crimes that cause direct human injury being perceived as less deserving of quality care than those who perpetrate crimes with indirect human harm (Handtke et al., 2017; Penrod et al., 2014; Turner et al., 2018). Whilst the public voice is an important factor, it can also serve as a barrier to end-of-life decision making as fears of public dissatisfaction can blinker perspectives (Handtke et al. 2017).

Overall, the integration of prison philosophy with hospice philosophy (e.g. custody versus care) is challenging, leading to ambiguity (Handtke et al., 2017; Hoffman and Dickinson, 2011; Penrod et al., 2014;). Penological goals will ultimately prevail over humanitarian grounds such as compassion (Handtke et al., 2017), with psychosocial concerns unlikely to be prioritised. 


\section{Prison processes, resources and provider attitudes}

Three articles gave details on how prison processes impacted on prisoner care (Loeb et al., 2014; Papadopoulos and Lay, 2016; Pazart et al., 2018). Barriers were identified as lockdown periods, no open-door policies, unsuitable bedding and diets, lack of privacy and questionable hygiene schedules. Lack of material resources and the nursing of incarcerated individuals in prison cells after hours were of concern. Comments from participants such as "the beds themselves don't work" or "I can't go outside because I'm tied to the electric [oxygen] concentrator" provide insights on how prison processes and resources impact on an incarcerated person's EOL journey (p. 177).

Three articles revealed some correctional staff do not agree with the incarcerated persons' caregiving program (Depner et al., 2018; Hoffman and Dickinson, 2011; Loeb et al., 2014). One caregivingparticipant stated "I guess they [correctional staff] don't understand or like what we do. Maybe they feel that as a prisoner or something that we are not supposed to have a peaceful end" (Depner et al., 2018, p. 974). However, it is important to add, two articles featured positive anecdotes regarding staff interactions (Loeb et al., 2014; Papadopoulos and Lay, 2016). One participant said, "they treat you well...they do what they have to, to get the job done with limited resources" (Loeb et al., 2014, p. 177).

\section{Understanding/Knowledge and mistrust}

Mistrust of prison and medical staff, as evidenced by statements such as "they may want to kill me quicker" or "they want to experiment on us", compounded with a lack of comprehension and understanding of their health status left incarcerated individuals "paralysed, unable to move forward with ACP" (Sander et al., 2018, p. 49). Limited knowledge on provisions for early medical release could explain its underutilization, with one study showing $76 \%$ of participants expressed a desire to apply once aware of the option (Kanbergs et 
al., 2019). These findings were similar to results derived in other European countries (Pazart et al., 2018).

\section{Facilitators}

\section{Incarcerated persons' caregiving programs}

Ten of the inclusion articles featured the benefits of the inmate volunteer program (Chassagne et al., 2017; Cloyes et al., 2014; Cloyes et al., 2015a; Cloyes et al., 2015b, Cloyes et al., 2017; Depner et al., 2017; Depner et al., 2018; Hoffman and Dickinson, 2011; Loeb et al., 2013; Supiano et al., 2014). Inmate caregivers were able to build trust and connections with the palliative inmates, which could assist in overcoming the identified barrier of mistrust. They were also a key source of information for health practitioners (Depner et al., 2018). The articles written by Cloyes et al. (2014; 2015a; 2015b) and Depner et al. $(2017 ; 2018)$ revealed benefits such as lower levels of reported discomfort and agitation, high levels of psychological, social, and spiritual support and feelings of connectedness through shared humanity. The volunteer program was thought to account for lower symptom prevalence on admission and better symptom control during the disease trajectory (Cloyes et al., 2015b). Inmates play a key role in "facilitating a comfortable and peaceful death", often serving as surrogate family members at a most vulnerable time (Depner et al., 2018, p. 976).

\section{A sense of purpose}

Eight articles specifically highlighted the positive effect on the incarcerated caregivers providing EOL care (Cloyes et al., 2014; Cloyes et al., 2015a; Cloyes et al. 2015b; Depner et al., 2017; Depner et al., 2018; Loeb et al., 2013; Loeb et al., 2014; Supiano et al., 2014). Caregivers perceived their role as opportunities to "give back", to express humanity, to undertake "God's work" and "having a God kind of heart" (Cloyes et al., 2014, p.744). The transformative change within caregiving volunteers aligns with a distinct prison goal rehabilitation; with more "prosocial behaviour" being noted (Depner et al., 2018, p. 977) and 
therefore could help to find alignment between the identified conflicting humanitarian and prison goals (Handtke et al., 2017). The results revealed that offending behaviour did not rob incarcerated persons of their capacity to care for others, providing "a sense purpose" (Depner et al., 2018, p. 975).

\section{Visitation leniency}

Five studies highlighted that visitor restrictions from family and friends were eased in many facilities as terminally ill incarcerated persons approached death (Hoffman and Dickinson, 2011; Lillie et al., 2018; Loeb et al., 2014; Penrod et al., 2018; Sanders et al., 2018). Hoffman and Dickinson's (2011) study revealed in 29\% of prison hospice programs family members could visit up to five times per week, with further flexibility shown when the prisoner's condition worsened. Both Hoffman and Dickinson (2011) and Lillie et al. (2018) discussed the instance of incarcerated family members; a minority population that could be readily overlooked. The process of arranging a visit from an incarcerated relative was “burdensome", however, worth all efforts (Lillie et al., 2018, p. 371).

Question 3 - How are human rights considered when addressing needs of terminally ill prisoners?

Whilst there is a body of literature promoting the relationship between palliative care and human rights, there were no empirical studies within our final selection, that focussed specifically on the promotion of palliative care as an essential human right. However, the findings revealed many jurisdictions have policies, such as advanced care planning (ACP), do not resuscitate (DNR) orders and compassionate release (CR) that have potential to advance or hinder incarcerated persons' human rights. It is also acknowledged that human rights and palliative care is much broader than ACP, DNR and CR policies.

Human rights principles, individual agency and dying with dignity, were highlighted in two articles (Ekaireb et al., 2018; Sanders et al., 2018). However, engagement with ACP was 
impeded by the incarcerated person's inability to articulate their wishes due to "not being told how sick they were" and "not having treatment options fully explained to them" (Sanders et al., 2018, p. 49). When individuals were able to engage in ACP, they found it an "empowering opportunity" using words such as "thankful" and "relieved" to be heard (Sanders et al., 2018, p. $48-50)$.

There are disparities regarding DNR orders, which raise questions regarding the human rights principles of self-determination. Some correctional institutions request incarcerated persons sign a DNR form to receive hospice care (Hoffman and Dickinson, 2011; Loeb et al., 2018), whereas others refuse them the right to sign. A study by Ekaireb et al. (2018) demonstrate this by quoting one physician: "if someone is sentenced to five years for a crime, it's the physician's responsibility to ensure the person serves those five years. Therefore, the person can't choose to be DNR or forgo treatment that would result in an early death" (p. 2384).

Handtke et al. (2017) highlight the complexities surrounding the release of terminally ill persons based on compassionate grounds and the principle of equivalence. A legal regulation for release "based on compassion is permanently applicable" (p. 237), irrespective of availability of EOL care in prison. However, if legal regulations are based on the principle of equivalence, then the terminally ill person must have access to appropriate EOL care, or this could result in a serious human rights violation.

\section{Discussion}

The aim of this study was to explore the psychosocial aspects of palliative care for incarcerated persons from a human rights perspective. The LSP in-prison hospice program utilising incarcerated peers as caregivers is an effective initiative due to its cost effectiveness and alignment with prison 'rehabilitation' goals. Undoubtedly, caregivers were positively 
impacted by this activity and prosocial behaviour was enhanced. However, Cloyes et al. (2017) questioned the ethics of this use of human capital. Psychosocial concerns of terminally ill incarcerated individuals, such as psychological and existential despair or heightened anxiety are usually addressed by specialist staff. Incarcerated caregivers referring to their assignment as a "calling from God" (Cloyes et al., 2014, p. 741) raises questions of belief imposition. Further research is required to explore the ethical aspects of these programs and who is best equipped to provide psychosocial services to the dying in a prison context.

The care versus custody tension is a delicate topic that is universally debated. Public and staff safety must be balanced with appropriate care for a terminally ill prisoner. Whilst it is understood that security risks prevent the release for prisoners deemed "dangerous", unanswered questions remain whether their rights for psychosocial care can be met behind prison walls. Sub-standard or denial of health care should never be part of a punishment as emphasised by the AHA (2019). Psychosocial care should therefore be promoted as an important human right for all persons, regardless of their legal status, and a "dignified death" as outlined by the United Nations (2017, p. 10), should be enabled.

Prisoner knowledge about their disease was connected to a mistrust of correctional systems, resulting in an impasse. Health care staff sought to record prisoner preferences via ACP discussions, however, some prisoners lacked trust that their wishes would be upheld, so were reluctant to engage (Sanders et al., 2018). Identified barriers to ACP such as, negative staff views towards prisoners, uncertainty regarding who should initiate discussions and policies that inhibited family and friends' involvement in medical decision-making processes require immediate attention (Ekaireb et al., 2018). As stated by the AHA (2019), terminally ill incarcerated persons could be encouraged to speak up about their needs; however, this is unlikely to occur in the current milieu of mistrust. If the human rights principle of equivalence is to be upheld in a prison context, then provisions should be made for an ally to be present 
during end-of-life or ACP discussion, as occurs in the community. This could diminish prisoner anxiety regarding making important decisions about their care within a punitive context. Furthermore, correctional and medical staff require education regarding the importance of unbiased attitudes, given its potential to impact on engagement with important discussions regarding care (Heidari et al., 2017).

There are different laws pertaining to DNR orders and ACP between and within countries. As discussed, in some countries incarcerated persons are required to sign DNR forms to access hospice care. In Australia, if an incarcerated person wishes to complete an Advance Care Directive these can be over-ruled and resuscitation enforced (AHA, 2019). Although the principles of self-determination are enshrined in human rights literature, the notion of patient centred care that is commonly associated with the philosophy of palliative care is therefore challenged in this context. As revealed by the findings, incarcerated persons are often unwilling to engage in ACP discussions due to mistrust and a reduced sense of agency, which aligns with government reports (AHA, 2019). Furthermore, it should be added, human rights and palliative care extend beyond ACP and DNR policy, with a keen emphasis on alleviation of physical and psychosocial suffering, despite one's legal status. As highlighted in the literature review, suffering is more encompassing than merely addressing physical pain (WHO, 2002). We therefore assert further research is required that involves going beyond prison walls and hearing the voices of incarcerated persons themselves or closely associated advocates regarding what they identify their psychosocial needs to be.

This research did not unearth articles on all psychosocial domains; for example, cultural concerns did not appear in any of the studies, besides a brief mention by Panozzo et al. (2020). This topic also warrants further exploration. Supiano et al. (2014) was the only article to illuminate the role of social work in the psychosocial sphere illuminating how social workers can play a key role in bereavement care, a necessary support once a prisoner dies after being 
cared for by an incarcerated caregiver. Social workers are well reputed for their psychosocial expertise, so therefore belong at the inter-disciplinary table. They can adequately address the psychosocial needs of terminally ill prisoners with both practical and therapeutic interventions.

These findings have significant policy implications. Human rights article 25 declares prisoners have a right to access health care, with the inclusion of necessary social services (United Nations, 1948). The authors purport this would include psychosocial care services. Despite increased advocacy for the rights of prisoners and WHO directives, penological goals triumph and psychosocial concerns such as anxiety, existential distress, fears of dying alone or behind bars do not appear prioritised and are often left to be addressed by peers. Caution needs to be exercised as causing an individual to experience fear can breach Article 5 relating to inhumane treatment (United Nations, 1948). Public education on the goals of prison (punishment and rehabilitation) and its questionable relevance when a prisoner is terminally ill would enhance awareness. As stated by Maschi et al. (2014) "society at large must move beyond thinking that fosters the punishment paradigm to a more compassionate palliative approach [with the inclusion of psychosocial care] that all humans deserve" (p. 192).

\section{Study limitations:}

There is inconsistency in the literature regarding what constitutes psychosocial care, which meant the authors needed to draw on multiple literature sources to formulate a definition Additionally, the review only included studies written in English, meaning some high-quality studies could have been missed. The articles that conducted interviews with incarcerated individuals were undertaken in male prisons only and not female prisons. Regarding human rights and palliative care, the final selection only included articles on ACP, DNR and CR, which are based on human rights principles but did not cover broader concepts relating to this topic. 


\section{Conclusion}

This systematic literature review explored three questions regarding psychosocial aspects of palliative care in prisons, conceptualised through a human rights lens. The question relating to barriers and facilitators for psychosocial care was mostly answered via the articles that focussed on incarcerated persons' caregiving programs. Other forms of psychosocial care were notably absent such as, cultural or religious rituals, making amends to victims, or family reconciliation. Further research will assist countries such as Australia and Switzerland to move forward in their development of psychosocial care in a prison context. As access to palliative care is a basic human right; the right to "necessary social services" cannot be overlooked (United Nations, 1948). Policy makers are required to review palliative care provision using a human rights perspective to adopt palliative care philosophy in its entirety.

\section{References}

Age UK. (2019). "Ageing prison population inquiry. (Report No. 1619)", available at: https://www.ageuk.org.uk/globalassets/age-uk/documents/reports-andpublications/consultation-responses-and-submissions/care-- 
support/justice_committee_ageing_prison_population_inquiry_submission_october2019.pdf (accessed 20 August 2020).

Australian Healthcare Associates. (2019). "Exploratory analysis of barriers of palliative careissues report on people who are incarcerated", available at:

https://www.health.gov.au/resources/publications/exploratory-analysis-of-barriers-topalliative-care-issues-report-on-people-who-are-incarcerated_(accessed 20 August 2020).

Australian Institute of Health and Welfare [AIHW]. (2014). "Prisoner health services in Australia 2012. (Bulletin No. 123)", available at: https://www.aihw.gov.au/getmedia/b80b7d02-7238-4fc1-96ed742f38bb9844/17454.pdf.aspx?inline=true_(accessed 1 November 2020).

Australian Institute of Health and Welfare [AIHW] (2019). "The health of Australia's prisoners 2018", available at: https://www.aihw.gov.au/reports/prisoners/health-australiaprisoners-2018/contents/table-of-contents_(accessed 1 November 2020)

Australian Institute of Health and Welfare [AIHW]. (2020). "Health of Prisoners" available at: https://www.aihw.gov.au/reports/australias-health/health-of-prisoners_(accessed 12 December 2020)

Braun, V. and Clark V. (2006). "Using thematic analysis in psychology", Qualitative Research in Psychology, Vol 3, 77-101.

Brennan, F. (2007). "Palliative Care as an International Human Right". Journal of Pain and Symptom Management, Vol 33 No. 5, pp. 494-499.

Chassagne, A., Godard, A., Cretin, E., Pazart, L. and Aubry, R. (2017). "The collision of inmate and patient: end-of-life issues in French prisons", Journal of Correctional Health Care, Vol 23 No. 1, pp. 66-75.

Cloyes, K. G., Rosenkranz, S. J., Wold, D., Berry, P. H. and Supiano, K. P. (2014). "To be truly alive: motivation among prison inmate hospice volunteers and the transformative process of end-of-life peer care service", American Journal of Hospice and Palliative Medicine, Vol 31 No. 7, pp. 735-748.

Cloyes, K. G., Rosenkranz, S. J., Berry, P. H., Supiano, K. P., Routt, M., Shannon-Dorcy, K. and Lianque, S. (2015a). "Essential elements of an effective and sustainable prison hospice program”, American Journal of Hospice \& Palliative Medicine, Vol 33 No. 4, pp. 390-402.

Cloyes, K. G., Berry, P. H., Martz, K. and Supiano, K. (2015b). "Characteristics of prison hospice patients: medical history, hospice care, and end-of-life symptom prevalence", Journal of Correctional Health Care, Vol 21 No. 3, pp. 298-308.

Cloyes, K. G., Rosenkranz, S. J., Supiano, K. P., Berry, P. H., Routt, M., Llanque, S. M. and Shannon-Dorcy, K. (2017). "Caring to learn and learning to care: Inmate hospice volunteers and the delivery of prison end-of-life care:, Journal of Correctional Health Care, Vol 23 No. 1, pp. 43-55.

Depner, G., Byrwa, D., Lodi-Smith, L. and Kerr, J. (2018). "People don't understand what goes on in here": A consensual qualitative research analysis of inmate-caregiver perspectives on prison-based end-of-life care", Palliative Medicine, Vol 32 No. 5. pp. 969-979.

Depner, R. M., Grant, P. C., Byrwa, D. J., Breier, J. M., Lodi-Smith, J., Kerr, C. W. and Luczkiewicz, D. L. (2017). "A consensual qualitative research analysis of the experience of 
inmate hospice caregivers: posttraumatic growth while incarcerated", Death studies, Vol 41 No. 4, pp. 199-210.

Ekaireb, R., Ahalt, C., Sudore, R., Metzger, L. and Williams, B. (2018). "We take care of patients, but we don't advocate for them": advance care planning in prison or jail. Journal of the American Geriatrics Society, Vol 66 No. 12, pp. 2382-2388.

Federal Bureau of Prisons (2020). "Inmate Age", available at:

https://www.bop.gov/about/statistics/statistics_inmate_age.jsp (accessed 1 November 2020).

Gledhill, A., Harwood, C. and Forsdyke, D. (2017). Psychosocial factors associated with talent development in football. Psychology of Sport and Exercise, Vol 31, pp. 93-112.

Handtke, V., Wangmo, T., Elger, B. and Bretschneider, W. (2017). New guidance for an old problem: Early release for seriously ill and elderly prisoners in Europe. The Prison Journal, Vol. 97 No. 2, pp. 224-246.

Heidari, R., Wangmo, T., Galli, S., Shaw, D. and Elger, B. (2017). “Accessibility of prison healthcare for elderly inmates, a quality assessment", Journal of Forensic and Legal Medicine, Vol. 52, pp. 223-228.

Hoffman, H. C. and Dickinson, G. E. (2011). Characteristics of prison hospice programs in the United States. American Journal of Hospice and Palliative Medicine, Vol 28 No. 4, pp. 245-252.

Holland, M., Prost, S. G., Hoffmann, H. and Dickinson, G. (2020). “Access and utilization of compassionate release in state departments of corrections", Mortality, pp. 1-17.

Hong, Q. N., Pluye P., Fàbregues, S., Bartlett, G., Boardman, F., Cargo. M., Dagenais, P., Gagnon, M. P., Griffiths, F., Nicolau, B., O’Cathain, A., Rousseau, M.C., and Vedel, I. Mixed Methods Appraisal Tool (MMAT), version 2018. Registration of Copyright (\#1148552), Canadian Intellectual Property Office. Industry, Canada.

Kanbergs, A., Ahalt, C., Cenzer, I. S., Morrison, R. S. and Williams, B. A. (2019). "No One Wants to Die Alone": Incarcerated Patients' Knowledge and Attitudes About Early Medical Release", Journal of Pain and Symptom management, Vol 57 No. 4, pp. 809-815.

Lillie, K., Corcoran, M., Hunt, K., Wrigley, A. and Read, S. (2018). "Encountering offenders in community palliative care settings: challenges for care provision", International Journal of Palliative Nursing, Vol 24 No. 8, pp. 368-375.

Loeb, S. J., Hollenbeak, C. S., Penrod, J., Smith, C. A., Kitt-Lewis, E. and Crouse, S. B. (2013). "Care and companionship in an isolating environment: inmates attending to dying peers", Journal of Forensic Nursing, Vol 9 No. 1, pp. 35-44.

Loeb, S. J., Penrod, J., McGhan, G., Kitt-Lewis, E. and Hollenbeak, C. S. (2014). "Who wants to die in here? Perspectives of prisoners with chronic conditions". Journal of Hospice and Palliative Nursing, Vol 16 No. 3, pp. 173-181.

Loeb, S. J., Wion, R. K., Penrod, J., McGhan, G., Kitt-Lewis, E. and Hollenbeak, C. S. (2018). A toolkit for enhancing end-of-life care: An examination of implementation and impact. The Prison Journal, Vol 98 No. 1, pp. 104-118.

Marti, I., Hostettler, U. and Richter, M. (2017). "End of life in high-security prisons in Switzerland: overlapping and blurring of "care" and "custody" as institutional logics. Journal of Correctional Health Care, Vol 23 No. 1, pp. 32-42. 
Maschi, T., Marmo, S. and Junghee, H. (2014). "Palliative and end-of-life care in prisons: a content analysis of the literature", International Journal of Prisoner Health, Vol 10 No. 3. pp. 172-197.

Maschi, T. and Richter, M. (2017). "Human rights and dignity behind bars: a reflection on death and dying in world prisons", Journal of Correctional Health, Vol 23 No. 1, pp. 76-82.

McParland, C. and Johnston, B. M. (2019). "Palliative and end of life care in prisons: a mixed-methods rapid review of the literature from 2014-2018", BMJ Open, Vol 9 No. 12, pp. $1-18$.

Merkt, H., Haesen, S., Meyer, L., Kressig, R. W., Elger, B. S., and Wangmo, T. (2020).

Defining an age cut-off for older offenders: a systematic literature

review. International Journal of Prisoner Health, Vol 16 No. 2, pp. 95-116.

Moher, D., Liberati, A., Tetzlaff, J. and Altmann, G. (2009). "Preferred Reporting Items for Systematic Reviews and Meta Analysis: the PRISMA statement", PLOS Medicine, Vol 6 No. 7, pp. 1-6.

Ong, C. K. and Forbes, D. (2005). "Embracing Cicely Saunders's concept of total pain”, $B M J$, Vol 331 No. 7516, pp. 576-577.

Penrod, J., Loeb, S. J. and Smith, C. A. (2014). “Administrators' Perspectives on Changing Practice in End-of-Life Care in a State Prison System", Public Health Nursing, Vol 31 No. 2, pp. 99-108.

Panozzo, S., Bryan, T., Collins, A., Marco, D., Lethborg, C. and Philip, J. A. (2020). "Complexities and constraints in end of life care for hospitalised prisoner patients", Journal of Pain and Symptom Management, Vol. 60 No. 5, pp. 984-991.

Papadopoulos, I. and Lay, M. (2016). "Current and emerging practice of end-of-life care in British prisons: findings from an online survey of prison nurses", BMJ Supportive \& Palliative Care, Vol 6 No. 1, pp. 101-104.

Pazart, L., Godard-Marceau, A., Chassagne, A., Vivot-Pugin, A., Cretin, E., Amzallag, E. and Aubry, R. (2018). "Prevalence and characteristics of prisoners requiring end-of-life care: a prospective national survey", Palliative medicine, Vol 32 No. 1, pp. 6-16.

Price, M. (2018). "Everywhere and nowhere: compassionate release in the States", available at: https://famm.org/wp-content/uploads/Exec-Summary-Report.pdf (accessed 30 November 2020)

Puru. L. (2018). “Access to palliative care services in prison: who cares?”, Whitireia Nursing and Health Journal, Vol 25, pp. 53-59.

Reith, M. and Payne, M. (2009). "Social work in end-of-life and palliative care", The Policy Press. Bristol, UK.

Sanders, S., Stensland, M. and Juraco, K. (2018). "Agency behind bars: advance care planning with aging and dying offenders", Death Studies, Vol 42 No. 1, pp. 45-51.

Sheldon, F. (1997). "Psychosocial palliative care: good practice in the care of the dying and bereaved". Stanley Thornes Publishers Ltd, Cheltenham, UK.

Stajduhar, K. I., Mollison, A., Giesbrecht, M., McNeil, R., Pauly, B., Reimer-Kirkham, S., ... \& Kvakic, K. (2019). "Just too busy living in the moment and surviving": barriers to 
accessing health care for structurally vulnerable populations at end-of-life." BMC Palliative Care, Vol. 18 No. 1, pp. 1-14.

Stephens, S., Cassell, J. B., Noreika, D. and Del Fabbro, E. (2019). "Palliative care for inmates in the hospital setting", American Journal of Hospice and Palliative Medicine, Vol 36 No. 4, pp. 321-325.

Supiano, K. P., Cloyes, K. G. and Berry, P. H. (2014). "The grief experience of prison inmate hospice volunteer caregivers", Journal of social work in end-of-life \& palliative care, Vol 10 No. 1. pp. 80-94.

Turner, M., Payne, S. and Barbarachild, Z. (2011). "Care or custody? An evaluation of palliative care in prisons in North West England", Palliative medicine, Vol 25 No. 4, pp. 370377.

Turner, M., Peacock, M., Payne, S., Fletcher, A. and Froggatt, K. (2018). "Ageing and dying in the contemporary neoliberal prison system: Exploring the 'double burden' for older prisoners”, Social Science \& Medicine, Vol 212, pp. 161-167.

United Nations. (2017). "The right to end-of-life palliative care and a dignified death", available at https://www.un.org/development/desa/ageing/wpcontent/uploads/sites/24/2017/11/ECLAC-contribution.pdf (accessed 30 July 2021).

United Nations. (1948). "Universal Declaration of Human Rights", available at: https://www.un.org/en/universal-declaration-human-rights/_(accessed 3 November 2020).

United Nations. (1966). "International Covenant on Civil and Political Rights", available at: https://www.ohchr.org/EN/ProfessionalInterest/Pages/CCPR.aspx (accessed 3 November 2020).

Walmsley, R. (2019). "World Prison Population List", available at: https://www.prisonstudies.org/sites/default/files/resources/downloads/wppl_12.pdf (accessed 20 August 2018).

World Health Organization. (2002). "WHO definition of palliative care/WHO definition of palliative care for children", available at: http:/www.who.int/cancer/palliative/definition/en/ (accessed 8 August 2020)

World Health Organization. (2014). "Prisons and Health", available at: https://www.euro.who.int/_data/assets/pdf_file/0005/249188/Prisons-and-Health.pdf (accessed 12 November 2020) 